\title{
COVID19 and ophthalmology: a brief summary of the literature
}

\author{
Shruti Chandra $\mathbb{D}^{1} \cdot$ Declan Flanagan $^{1} \cdot$ Melanie Hingorani ${ }^{1} \cdot$ Andrew Lotery $^{2} \mathbb{D}^{2} \cdot$ Sobha Sivaprasad ${ }^{1}$
}

Received: 28 April 2020 / Revised: 29 April 2020 / Accepted: 30 April 2020 / Published online: 12 May 2020

(c) The Royal College of Ophthalmologists 2020

This literature review aims to address the available evidence on COVID19 related issues faced in ophthalmology practice.

Methods: Information was collected from published national guidance (Public Health England, Royal College of Ophthalmologists) and international guidance (World Health Organization, European Centre for Disease Control) for COVID19. PubMed search terms like "SARS-CoV-2", "conjunctiva", "transmission" and "aerosols" were used, synonyms captured and search lines merged with Boolean operators "AND" and "OR".

\section{Evidence of virus in ocular tissue}

The nasal portal is the most common route of entry for SARS-CoV-2 virus [1]. To facilitate cellular entry, the spike protein (S) of the SARS-CoV-2 virus binds to the ACE2 receptor and is then primed by proteases such as TMPRSS2 and this binding affinity determines the viral load and disease severity. However, other proteases may also be involved [2]. In the eye, ACE2 and TMPRSS2 co-localise in the corneal epithelium [2]. Conjunctivitis is a rare manifestation [3] and transmission through ocular secretions is also low [4].

\section{Evidence on modes of transmission to Ophthalmology staff}

Out-patient setting: the most likely route of transmission in ophthalmology is via aerosol spread of virus especially due

Shruti Chandra

shruti.chandra@nhs.net

1 National Institute of Health Research Moorfields Biomedical Research Centre, Moorfields Eye Hospital, London, UK

2 Faculty of Medicine, Clinical and Experimental Sciences, University of Southampton, Southampton, UK to close proximity during eye examination (close contact defined as $<2 \mathrm{~m}, 30 \mathrm{~min}$ ) [5]. Breathing or speech generating aerosols $(<1$ micron particle size) invisible to the naked eye are capable of carrying the virus [6], although fomite transmission is possible due to prolonged viability of virus on aerosols and surfaces [7]. Non-contact tonometry may generate microaerosols [8]. Transmission of respiratory viruses in hospital setting may also be aggravated by inadequate airflow, overcrowding, large temperature differences in rooms and rapid movement of air, which can increase the distance travelled by airborne particles [9].

Surgical setting: caution should also be exercised during surgical procedures involving the upper respiratory tract including nasal endoscopy and lacrimal procedures as these are aerosol generating procedures (AGP) [10]. Public Health England (PHE) has also included "surgery with high speed devices" as AGPs [11]. Reports on evidence of virusladen aerosol generation are published with orthopaedic and dental drills, however, there is lack of evidence on AGP properties of intraocular surgical instruments and no evidence of viral transmissibility from ocular or intraocular fluids especially as such instruments are used inside rather than on the surface of the eye $[12,13]$. The Royal College of Ophthalmologists with the British Eire Association of Vitreoretinal Surgeons (BEAVRS) and the United Kingdom \& Ireland Society of Cataract \& Refractive Surgeons [UKISCRS] have issued specific guidelines regarding pars plana vitrectomy (PPV) and phacoemulsification procedures that employ instruments with high speed cut rates (phacoemulsification probes, vitrectomy cutters) $[14,15]$. The guidance advises for suspension of non-elective surgeries and defines retinal detachment and cataract in the context of retinal detachment or glaucoma as urgent ophthalmic procedures. With due consideration to the unknown risk of infection, and a lack of conclusive evidence, the guidance recommends these procedures are seen as potential AGPs. However, further research is recommended regarding the need of Filtering Face Piece 3 (FFP3) respirators as well as eye protection by surgeons and scrub nurses while performing phacoemulsification cataract surgery and vitrectomy. 


\section{Evidence on Personal Protective Equipment (PPE)}

There are conflicting views worldwide on precisely how effectively masks protect healthcare workers, patients and the general public. Masks do provide high levels of respiratory protection and for this reason the American Academy of Ophthalmology, the Royal College of Ophthalmologists [RCOphth] and PHE have advised the use of masks when examining and treating all patients. Masks are classified based on filter efficacy and face adhesion: FFP 1 , 2 and 3 offer filter efficacy $80 \%, 94 \%$ and $99 \%$, respectively [16]. The Food and Drug Administration (FDA) regulatory requirement do not address the fit of surgical masks making the total filtration efficiency of questionable value [17]. Gloves, disposable aprons, eye protection, fluid resistant type IIR surgical masks (FRSM) and slit lamp guards are recommended as PPE for all ophthalmic clinic assessment and outpatient procedures (e.g. intravitreal injections) by the Royal College of Ophthalmologists [18]. This guidance is compliant with PHE recommendations for use of PPE [11]. For potential AGPs, the PHE and RCOphth guidance advises consideration of the use of single use FPP respirator, fluid resistant gown, gloves and eye protection. For high risk acute areas such as operation theatres where AGPs are performed and high dependency unit where ophthalmology review may be required, use of gloves plastic apron and FRSM with eye protection is recommended. The PHE recommends use of masks for all patients attending outpatient clinics and using communal waiting areas.

WHO encourages hand washing with alcohol gels and solutions, although there is limited evidence that these are superior to washing with soap and water in reducing viral load. PHE recommends all staff, patients and visitors should decontaminate their hands with alcohol-based hand rub (ABHR) when entering and leaving areas where patient care is being delivered [11].

The European Centre for Disease Prevention and Control (ECDC) recommends neutral soap and sodium hypochlorite $0.1 \%$ to clean equipment or ethanol ( $70 \%$ concentration) if specific formulations are lacking [19]. In the UK, PHE recommends patient care equipment should be cleaned where possible with chlorine-based disinfectant, $70 \%$ alcohol or an alternative disinfectant used within the organisation that is effective against enveloped viruses [11].

\section{Management of outpatient clinic attendance}

Ophthalmology has the highest annual patient attendance in the UK, with many patients being in the high-risk category [20]. Therefore, social distancing should be practiced for patients who attend eye clinic. Strategies to reduce infection transmission involve measures at administrative, hospital and individual levels [21]. Risk stratification of patients for various services is recommended by the Royal College of Ophthalmologists to reduce face to face consultation to a minimum. A recent article by Sim et al., reinforced the importance of tele-ophthalmology in the current crisis [22]. With changes and disruptions in services it remains unclear if and how many patients suffer vision loss and postpandemic audits would be crucial to identifying this data. In the meantime, robust emergency services and active "hotlines" should be made available for patients with sudden vision loss.

\section{Evidence on testing of health workers for COVID19}

Nosocomial transmission has been recognised as an important amplifier in epidemics of both SARS and Middle East respiratory syndrome. Although hospital settings are the most common sites for secondary transmission of SARS and MERS virus, it is not the case for COVID 19 and considerable transmission occur through close contacts [23]. The Newcastle upon Tyne Hospitals performed 1666 SARS-CoV-2 tests in 1654 staff between 10 and 31 March 2020. Overall, SARS-CoV-2 was detected in $240(14 \%)$ tests. To further explore the occupational role affected, staff were divided into three groups-direct patient facing roles, non-patient facing roles but potentially high risk and nonclinical roles. Most staff were in group 1 (834 [81\%] of 1029), with a minority in groups $2(86[8 \%])$ or 3 (109 [11\%]). However, comparison yielded no significant difference in rate of SARS-CoV-2 infection among the groups. They concluded that nosocomial infection from patients to staff was not an important factor-community spread played a larger role in transmission. Another important outcome from the testing protocol was that a large number of employees (1414) were able to return to work quickly even in direct patient facing roles. However, the limitations of the study were testing of a smaller cohort of non-clinical staff, lack of data on symptomatology and use of SARS-CoV-2 RdRp assay which has low sensitivity [24].

\section{Potential treatments for COVID19}

New or re-purposed drugs are being explored for treatment of COVID19. Ongoing trials that are treating patients with doses as high as $1 \mathrm{~g}$ daily of hydroxychloroquine (HCQ) for 10 days. However as retinal toxicity due to HCQ is dependent on cumulative dose and duration, the aforementioned doses are unlikely to cause retinal toxicity [25]. 
In conclusion, as of 30 April 2020, evidence on the implications of COVID19 in ophthalmology practice are limited to Level 2 or lower. Further research in this field is awaited.

Acknowledgements The research was supported by the National Institute for Health Research (NIHR) Biomedical Research Centre based at Moorfields Eye Hospital NHS Foundation Trust and UCL Institute of Ophthalmology. The views expressed are those of the author(s) and not necessarily those of the NHS, the NIHR or the Department of Health.

\section{Compliance with ethical standards}

Conflict of interest The authors declare that they have no conflict of interest.

Publisher's note Springer Nature remains neutral with regard to jurisdictional claims in published maps and institutional affiliations.

\section{References}

1. Zhou P, Yang XL, Wang XG, Hu B, Zhang L, Zhang W, et al. A pneumonia outbreak associated with a new coronavirus of probable bat origin. Nature 2020;579:270-3.

2. Sungnak W, Huang N, Becavin C, Berg M, Queen R, Litvinukova $\mathrm{M}$, et al. SARS-CoV-2 entry factors are highly expressed in nasal epithelial cells together with innate immune genes. Nat Med. 2020. https://doi.org/10.1038/s41591-020-0868-6.

3. Zhou Y, Zeng Y, Tong Y, Chen C. Ophthalmologic evidence against the interpersonal transmission of 2019 novel coronavirus through conjunctiva. medRxiv. 2020:2020.02.11.20021956. http:// medrxiv.org/content/early/2020/02/12/2020.02.11.20021956.

4. Xia J, Tong J, Liu M, Shen Y, Guo D. Evaluation of coronavirus in tears and conjunctival secretions of patients with SARS-CoV-2 infection. J Med Virol. 2020. https://doi.org/10.1002/jmv.25725.

5. Asadi S, Bouvier N, Wexler AS, Ristenpart WD. The coronavirus pandemic and aerosols: does COVID-19 transmit via expiratory particles? Aerosol Sci Technol. 2020;0:1-4. https://doi.org/10. 1080/02786826.2020.1749229.

6. Yan J, Grantham M, Pantelic J, Bueno de Mesquita PJ, Albert B, Liu $F$, et al. Infectious virus in exhaled breath of symptomatic seasonal influenza cases from a college community. Proc Natl Acad Sci USA. 2018;115:1081.

7. van Doremalen N, Bushmaker T, Morris DH, Holbrook MG, Gamble A, Williamson BN, et al. Aerosol and surface stability of SARS-CoV-2 as compared with SARS-CoV-1. N. Engl J Med. 2020;382:1564-7.

8. Britt JM, Clifton BC, Barnebey HS, Mills RP. Microaerosol formation in noncontact 'air-puff' tonometry. Arch Ophthalmol 1991;109:225-8.

9. Wilson P, Zumla A. Transmission and prevention of acute viral respiratory tract infections in hospitals. Curr Opin Pulm Med. 2019;25:220-4.

10. Tran K, Cimon K, Severn M, Pessoa-Silva CL, Conly J. Aerosol generating procedures and risk of transmission of acute respiratory infections to healthcare workers: a systematic review. PLoS ONE 2012;7:e35797.
11. England PH. COVID-19: infection prevention and control guidance $2020 \mathrm{https} / / /$ assets.publishing.service.gov.uk/government/ uploads/system/uploads/attachment_data/file/881242/COVID-19_ Infection_prevention_and_control_guidance_complete.pdf.

12. Putzer D, Lechner R, Coraca-Huber D, Mayr A, Nogler M, Thaler $M$. The extent of environmental and body contamination through aerosols by hydro-surgical debridement in the lumbar spine. Arch Orthop Trauma Surg. 2017;137:743-7.

13. Epstein JB, Rea G, Sibau L, Sherlock CH, Le ND. Assessing viral retention and elimination in rotary dental instruments. J Am Dent Assoc. 1995;126:87-92.

14. Surgeons RCoOBEAoV. Vitreoretinal surgery during the COVID-19 pandemic 6th April 2020. https://www.rcophth.ac. uk/wp-content/uploads/2020/04/Vitreoretinal-surgery-mana gement-guidance-070420-1.pdf.

15. [UKISCRS] RCoORaUKISoCRS. Cataract surgery during the COVID-19 pandemic 2020. https://www.rcophth.ac.uk/wpcontent/uploads/2020/04/RCOphth-UKISCRS-COVID-cataractsurgery-guidance-FINAL-170420.pdf.

16. European Centre for Disease Prevention and Control. Personal protective equipment (PPE) needs in healthcare settings for the care of patients with suspected or confirmed 2019-nCoV. Stockholm: ECDC; 2020.

17. Institute of Medicine of the National Academies. "Characteristics of Respirators and Medical Masks." Reusability of Facemasks During an Influenza Pandemic: Facing the Flu. Washington, DC: The National Academies Press; 2006. https://fdocuments.in/ document/reusability-of-facemasks-during-an-influenza-pa ndemic-facing-the-flu.html.

18. PPE and Staff Protection Requirements for Ophthalmology 9th April 2020. https://www.rcophth.ac.uk/wp-content/uploads/2020/ 04/UPDATED-RCOphth-PPE-for-ophthalmology-090420.pdf.

19. Lai MY, Cheng PK, Lim WW. Survival of severe acute respiratory syndrome coronavirus. Clin Infect Dis. 2005;41:e67-71.

20. Summary of Hospital Outpatient Activity 2018-19 2019. https:// digital.nhs.uk/data-and-information/publications/statistical/hospita 1-outpatient-activity/2018-19.

21. Lai THT, Tang EWH, Chau SKY, Fung KSC, Li KKW. Stepping up infection control measures in ophthalmology during the novel coronavirus outbreak: an experience from Hong Kong. Graefes Arch Clin Exp Ophthalmol. 2020. https://doi.org/10.1007/s00417020-04641-8.

22. Dawn Sim PT, Chris Canning. Tackling COVID-19 with Telemedicine 2020. https://theophthalmologist.com/subspecialties/ta ckling-covid-19-with-telemedicine.

23. Wu Z, McGoogan JM. Characteristics of and important lessons from the Coronavirus Disease 2019 (COVID-19) Outbreak in China: summary of a report of 72314 cases from the chinese center for disease control and prevention. Jama. 2020. https://doi. org/10.1001/jama.2020.2648.

24. Chan JF, Yip CC, To KK, Tang TH, Wong SC, Leung KH, et al. Improved molecular diagnosis of COVID-19 by the novel, highly sensitive and specific COVID-19-RdRp/Hel real-time reverse transcription-PCR assay validated in vitro and with clinical specimens. J Clin Microbiol. 2020;58. https://doi.org/10.1128/jcm. 00310-20.

25. Marmor MF. COVID-19 and Chloroquine/Hydroxychloroquine: is there ophthalmological concern? Am J Ophthalmol. 2020. https://doi.org/10.1016/j.ajo.2020.03.028. 